\title{
Analisis Penerapan Model UTAUT Terhadap Perilaku Pengguna E-Learning (Studi Kasus : STMIK STIKOM Bali)
}

\author{
I Wayan Gede Narayana \\ Prodi Sistem Komputer, STMIK STIKOM Bali \\ narayana@stikom-bali.ac.id
}

\begin{abstract}
The information technology usage which is getting popular makes lots of user change course to utilize that technology especially web, in which in stmik stikom bali there is a web-based system,called elearning, which is very needed. UTAUT model model is used to know the behaviour in using this system. In this research, it will be restricted on the influence analysis of Performance Expectancy, Effort Expectancy, Social Influence, and Faciliting Condition whereas in this research the subjects are the students as users of the system by using PLS (Partial Least Square) as the data processing. The result of the research is that there are 4 independent variables (Performance Expectancy, Effort Expectancy, Social Expectancy, and Facilitating Condition) which are connected with the dependent variable (Behaviour in Use System), there is only 1 variable which has positive influence
\end{abstract}

Keywords : E-Learning, UTAUT, PLS

\begin{abstract}
ABSTRAK
Penggunaan teknologi informasi yang semakin popular membuat pengguna semakin banyak beralih pada teknologi tersebut khususnya web, dimana pada STMIK STIKOM Bali terdapat system informasi berbasis web yaitu elearning yang sangat dibutuhkan. Dengan menggunakan model UTAUT (Unified Theory of Acceptance and Use of Technology) untuk mengetahui perilaku dalam menggunakan system informasi. Dalam penelitian ini akan dibatasi untuk analisis pengaruh Performace Expectancy, Effort Expectancy, Social Influence dan Faciliting Condition. Dimana dalam penelitian ini akan dilakukan pada mahasiswa sebagai pengguna sistem dengan menggunakan PLS (Partial Least Square) sebagai pengolahan data. Hasil dari penelitian didapat dimana dari 4 variable bebas (Performace Expectancy, Effort Expentancy, Social Influence dan Faciliting Condition )yang dihubungkan dengan variable terikat (Behavior In Use System )hanya 1 variable yang memiliki pengaruh positif.
\end{abstract}

Kata Kunci : E-Learning, UTAUT, PLS 


\section{PENDAHULUAN}

Teknologi sudah menjadi kewajiban dalam penerapan tugas apapun yang dilaksanakan, dalam beberapa pekerjaan teknologi menjadi prioritas yang paling utama untuk mencapai tujuan. Dalam beberapa hal penggunaan teknologi informasi harus lebih mampu ditingkatkan untuk dapat bersaing. Oleh karena itu penting untuk memacu tingkat pemanfaatan dan penggunaan teknologi informasi di organisasi. Keberadaan teknologi informasi tidak bisa dilepaskan peranannnya dalam proses pengerjaan tugas karyawan[1]. Keberhasilan dalam melaksanakan tugas tersebut akan sangat ditentukan kualitas kinerja teknologi informasi dalam pembelajaran terhadap mahasiswa, yang akan terus dikembangkan secara luas untuk memenuhi era globalisasi [2]. Sistem informasi akan membantu organisasi untuk menyajikan informasi secara cepat, akurat dan terbuka seperti yang diharapkan oleh masyarakat. Masyarakat saat ini mempunyai pemikiran maju yang lambat laun akan meninggalkan cara-cara manual dan membuat terobosan baru untuk mendapatkan informasi. Dalam banyaknya system informasi yang dibangun di suatu institusi ataupun di perusahaan, ada beberapa penerapannya yang tidak maksimal sehingga penggunannya juga tidak sesuai dengan harapan. Pada STMIK STIKOM Bali terdapat system informasi online untuk pembelajaran yaitu E-learning, dimana pada system ini dosen dan mahasiswa mampu melakukan interaksi dalam kegiatan pembelajaran seperti share materi, upload tugas, quis dan forum diskusi. Dalam penggunaan e-learning ini diharapkan pengguna (dosen dan mahasiswa ) mampu memanfaatkan dengan baik dan memaksimalkan penggunaan dalam peningkatan pemahaman materi yang diberikan.

UTAUT merupakan sebuah model untuk menjelaskan perilaku pengguna terhadap teknologi informasi [2] dalam [1]. Model ini merupakan kombinasi dari delapan model yang telah berhasil dikembangkan sebelumnya. Model UTAUT menunjukan bahwa niat untuk berperilaku (behavioral intention) dan perilaku untuk menggunakan suatu teknologi (use behavior) dipengaruhi oleh harapan akan kinerja (performance expectancy), harapan akan usaha (effort expectancy), pengaruh sosial (social influence), dan kondisi pendukung (facilitating conditions). Keempat Faktor tersebut dimoderasi oleh faktor jenis kelamin (gender), usia (age), pengalaman (experience) dan kesukarelaan menggunakan (voluntariness of use). Studi empiris yang mengadopsi model ini telah banyak dilakukan, dan mendapatkan temuan yang beragam.

Dalam penelitian ini akan dibahas pengaruh performance expectancy, effort expectancy, social influence dan facilitating condition terhadap perilaku penggunaan elearning. Diharapkan dengan menerapkan model UTAUT dapat menjelaskan perilaku pengguna e-learning. Dengan demikian pimpinan akan memberikan kebijakan penggunaan tepat elearning.

\section{TINJAUAN PUSTAKA}

\section{E-Learning}

Web Based Training merupakan salah satu bentuk bahan ajar ELearning yang membutuhkan sebuah Web Browser untuk mengaksesnya. Selain itu juga Web Based Training juga memerlukan sebuah jaringan internet untuk dapat mengaksesnya. Kelebihan dari Web Based Training adalah semua orang di dunia dapat mengaksesnya. Namun Web Based Training juga memiliki kekurangan, yaitu perlunya koneksi internet yang membuat media pembelajaran ini menjadi mahal. Selain itu juga kecepatan dalam mengakses materimateri yang ada dalam bahan ajar tersebut masih kurang. Berbeda dengan Web Based Training, Browser Based Training juga merupakan salah satu bentuk bahan ajar Elearning [4] 


\section{UTAUT}

UTAUT merupakan salah satu model penerimaan teknologi terkini yang dikembangkan oleh Venkatesh, dkk. UTAUT menggabungkan fitur-fitur yang berhasil dari delapan teori penerimaan teknologi terkemuka menjadi satu teori. Kedelapan teori terkemuka yang disatukan di dalam UTAUT adalah theory of reasoned action (TRA), technology acceptance model (TAM), motivational model (MM), theory of planned behavior (TPB), combined TAM and TPB, model of PC utilization (MPTU), innovation diffusion theory (IDT), dan social cognitive theory (SCT). UTAUT terbukti lebih berhasil dibandingkan kedelapan teori yang lain dalam menjelaskan hingga 70 persen varian pengguna [3]. Setelah mengevaluasi kedelapan model, Venkatesh, dkk. menemukan tujuh konstruk yang tampak menjadi determinan langsung yang signifikan terhadap behavioral intention atau use behavior dalam satu atau lebih di masingmasing model. Konstruk-konstruk tersebut adalah performance expectancy, effort expectancy, social influence, facilitating conditions, attitude toward using technology, dan self-efficacy. Setelah melalui pengujian lebih lanjut, ditemukan empat konstruk utama yang memainkan peran penting sebagai determinan langsung dari behavioral intention dan use behavior yaitu, performance expectancy, effort expectancy, social influence, dan facilitating conditions. Sedangkan yang lain tidak signifikan sebagai determinan langsung dari behavioral intention. Disamping itu terdapat pula empat moderator: gender, age, voluntariness, dan experience yang diposisikan untuk memoderasi dampak dari empat konstruk utama pada behavioral intention dan use behavior[5].Pada Gambar 1. menampilkan keterkaitan antara determinan-determinan dan moderator-moderator ini.

Tujuan utama penelitian menggunakan UTAUT adalah membantu organisasi untuk memahami bagaimana penggunaan bereaksi terhadap pengenalan teknologi baru dalam [1]. Pada awalnya, UTAUT dikembangkan dari Technology Acceptance Model (TAM) pada tahun 2003 dengan empat konstruk yang mempengaruhi niat perilaku untuk menggunakan teknologi yaitu: performance expectancy, effort expectancy, social influence, facilitating conditions. Sampai saat ini UTAUT sudah dikembangkan kembali dari konteks organisasi menjadi konteks konsumen individu yang diberi nama Model UTAUT2 di mana habit, hedonic motivation dan price value ditambahkan sebagai konstruksi baru[1].

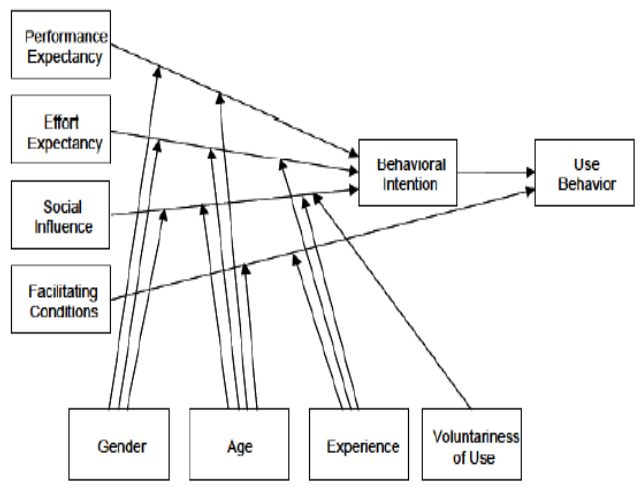

Gambar 1. Model UTAUT

(Source : Venkatest,dkk, 2003)

\section{Partial Least Square(PLS)}

PLS (Partial Least Square) adalah suatu metode untuk penciptaan dan pembangunan model dengan pendekatan yang berorientasi pada prediksi. PLS memiliki asumsi data penelitian bebas distribusi (Distribution Free), artinya data penelitian tidak mengacu pada salah satu distribusi tertentu (misalnya distribusi normal). PLS merupakan metode alternatif dari Structural Equation Modeling (SEM) yang dapat digunakan untuk mengatasi permasalahan hubungan diantara variabel yang kompleks namun ukuran sampel datanya kecil (30 sampai 100).

Dengan menggunakan metode PLS dapat diketahui kompleksitas hubungan suatu konstruk dan konstruk yang lain, serta hubungan suatu konstruk dan indikatorindikatornya. PLS didefinisikan oleh dua persamaan, yaitu inner model dan outer model. Inner model menentukan spesifikasi hubungan antara konstruk dan konstruk yang 
lain, sedangkan outer model menentukan spesifikasi hubungan antara konstruk dan indikator-indikatornya

\section{METODE PENELITIAN}

\section{Tempat dan Waktu Penelitian}

Penelitian dilaksanakan di STMIK STIKOM Bali selama 5 bulan dari bulan Agustus - Desember2016

\section{Sistematika Penulisan}

Sistematika penelitian ditunjukkan oleh Gambar 2. Masing-masing tahapan dapat dijelaskan sebagai berikut:

1. Tahap pertama adalah proses identifikasi hal-hal yang menjadi referensi penerapan model UTAUT. Proses ini dilaksanakan dengan melakukan Pemahaman di lapangan, Studi literatur, dan studi penelitian pendahulu. Hasil dari proses ini adalah analisis terhadap penerapan model UTAUT pada elearning STIKOM Bali .

2. Tahap berikutnya adalah pembentukan model konseptual dan rencana penelitian.

Dalam tahap ini proses yang dilakukan adalah Identifikasi variabel, bentuk hubungan antar konstruk, serta penyusunan hipotesis penelitian.Faktor yng akan disusun daam penelitian ini adalah dari waktu, konten, kualitas materi dan media. Hasil dari tahap ini adalah daftar dan deskripsi variabel serta instrumen penelitian. Instrumen penelitian disesuaikan dengan deskripsi variabel penelitian.

3. Tahap berikutnya adalah pengumpulan data, pengujian hipotesis, serta intepretasi hasil pengujian. Hasil dari pengujian hipotesis adalah hipothesis yang diterima atau ditolak.
4. Proses terakhir adalah pengambilan kesimpulan.
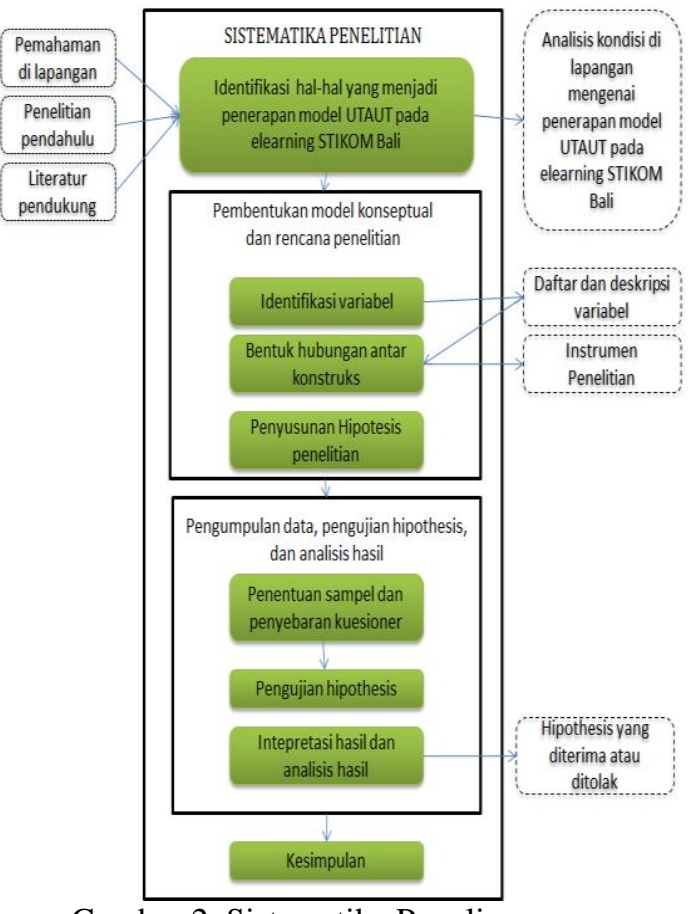

Gambar 2. Sistematika Penulisan

\section{Hipotesis}

Berdasarkan variabel penelitian maka hipotesis yang akan dibuktikan dalam penelitian ini adalah sebagai berikut:

Tabel 1. Hipotesis

\begin{tabular}{|l|l|}
\hline H1 & $\begin{array}{l}\text { Performacy Expectacy mempunyai } \\
\text { pengaruh positif terhadap Behavior In } \\
\text { Use System }\end{array}$ \\
\hline $\mathrm{H} 2$ & $\begin{array}{l}\text { Effort Expectacy mempunyai } \\
\text { pengaruh positif terhadap Behavior In } \\
\text { Use System }\end{array}$ \\
\hline $\mathrm{H} 3$ & $\begin{array}{l}\text { Social Influence mempuyai pengaruh } \\
\text { positif terhadp Behavior In Use } \\
\text { System }\end{array}$ \\
\hline H4 & $\begin{array}{l}\text { Facilitating Condition mempuyai } \\
\text { pengaruh positif terhadp Behavior In } \\
\text { Use System }\end{array}$ \\
\hline
\end{tabular}




\section{HASIL DAN PEMBAHASAN}

\section{Hasil Model} gambar 3

Hasil model pada dapat dilihat pada

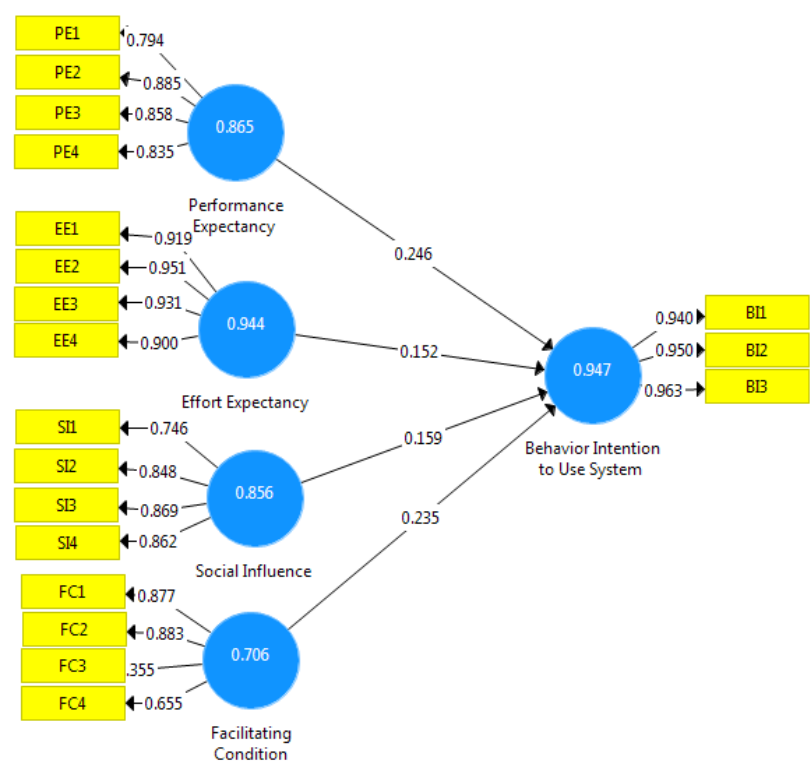

Gambar 3. Hasil Model

\section{Hasil Pengukuran Model \\ Convergent Validity}

Convergent validity dari model pengukuran dengan indikator refleksif dapat dilihat dari korelasi antara skor indikator dengan skor konstruknya. Indikator dianggap valid apabila memiliki nilai outer loading diatas 0,50. Melihat hasil pada Tabel 2 menunjukan bahwa indikator yang digunakan sudah dapat dianggap valid karena outer loading memiliki nilai diatas 0,50 .

Tabel 2. Hasil Convergent Validity

\begin{tabular}{|l|l|l|l|}
\hline \multicolumn{1}{|c|}{ Variable } & Indikator & \multicolumn{1}{c|}{$\begin{array}{c}\text { Outer } \\
\text { Loading }\end{array}$} & Ket \\
\hline $\begin{array}{l}\text { Performanc } \\
\text { e Expectacy }\end{array}$ & PE1 & 0.794 & Valid \\
\cline { 2 - 4 } & PE2 & 0.885 & Valid \\
\cline { 2 - 4 } & PE3 & 0.858 & Valid \\
\cline { 2 - 4 } & PE4 & 0.835 & Valid \\
\hline \multirow{2}{*}{$\begin{array}{l}\text { Effort } \\
\text { Expectacy }\end{array}$} & EE1 & 0.919 & Valid \\
\cline { 2 - 4 } & EE2 & 0.951 & Valid \\
\hline
\end{tabular}

\begin{tabular}{|c|c|c|c|}
\hline & EE3 & 0.931 & Valid \\
\hline & EE4 & 0.900 & Valid \\
\hline \multirow{4}{*}{$\begin{array}{l}\text { Social } \\
\text { Influence }\end{array}$} & SI1 & 0.746 & Valid \\
\hline & SI2 & 0.848 & Valid \\
\hline & SI3 & 0.869 & Valid \\
\hline & SI4 & 0.862 & Valid \\
\hline \multirow{4}{*}{$\begin{array}{l}\text { Facilitating } \\
\text { Condition }\end{array}$} & FC1 & 0.877 & Valid \\
\hline & FC2 & 0.883 & Valid \\
\hline & FC3 & 0.355 & $\begin{array}{l}\text { Not } \\
\text { Valid }\end{array}$ \\
\hline & FC4 & 0.655 & Valid \\
\hline \multirow{3}{*}{$\begin{array}{l}\text { Behavior In } \\
\text { Use System }\end{array}$} & IUS1 & 0.940 & Valid \\
\hline & IUS2 & 0.950 & Valid \\
\hline & IUS3 & 0.963 & Valid \\
\hline
\end{tabular}

\section{Discrimant Validity}

Discrimant validity merupakan pengukuran indikator dengan variabel latennya. Pengukuran discriminant validity dilakukan dengan cara melihat nilai akar AVE setiap konstruk. Apabila nilai akar AVE tiap konstruk memiliki nilai diatas 0,5 maka dapat disimpulkan konstruk tersebut memiliki nilai discriminant validity yang baik. Hasil pengujian menunjukan bahwa semua konstruk memenuhi kriteria discriminant validity yang baik seperti pada Tabel 3

Tabel 3. Hasil Discriminant Validity

\begin{tabular}{|l|l|}
\hline \multicolumn{1}{|c|}{ Varible } & Nilai AVE \\
\hline Performance Expectacy & 0.712 \\
\hline Effort Expectacy & 0.856 \\
\hline Social Influence & 0.694 \\
\hline Facilitating Condition & 0.526 \\
\hline Behavior In Use System & 0.905 \\
\hline
\end{tabular}

\section{Pengujian Realibilitas}

Selain uji validitas terhadap konstruk, dilakukan juga uji reliabilitas konstruk yang dapat diukur dengan kriteria 
composite reliability dan cronbach's alpha. Konstruk dapat dikatakan reliabel apabila nilai composite reliability dan cronbach's alpha-nya memiliki nilai diatas 0,60 . Hasil output composite reability dan cronbanch's alpha dapat dilihat pada Tabel 4 dan Tabel 5

Tabel 4. Hasil Composite Realibility

\begin{tabular}{|l|c|}
\hline \multicolumn{1}{|c|}{ Variable } & $\begin{array}{c}\text { Nilai } \\
\text { Composite Reliability }\end{array}$ \\
\hline Performance Expectacy & 0.908 \\
\hline Effort Expectacy & 0.960 \\
\hline Social Influence & 0.900 \\
\hline Facilitating Condition & 0.802 \\
\hline Behavior In Use System & 0.966 \\
\hline
\end{tabular}

Tabel 5. Hasil Cronbach's Alpha

\begin{tabular}{|l|c|}
\hline \multicolumn{1}{|c|}{ Variable } & $\begin{array}{c}\text { Nilai } \\
\text { Cronbach's Alpha }\end{array}$ \\
\hline Performance Expectacy & 0.865 \\
\hline Effort Expectacy & 0.944 \\
\hline Social Influence & 0.856 \\
\hline Facilitating Condition & 0.706 \\
\hline Behavior In Use System & 0.947 \\
\hline
\end{tabular}

\section{Hasil Evaluasi Model}

Model struktural dievaluasi dengan melihat nilai $R$-square untuk variabel dependen. Hasil perhitungan memperlihatkan nilai R2 sebesar 0,481 atau $48,1 \%$ artinya sebesar $45,1 \%$ variabel penerimaan $e$ learning STMIK STIKOM Bali dipengaruhi oleh variabel kemudahan dan kemanfaatan. Nilai $Q$-square dapat dihitung menggunakan persamaan 1 .

$Q$-square $=1-\left(1-(R \text {-square })^{2}\right)$

$Q$-square $=1-\left(1-(0,481)^{2}\right)=0.231361$

Berdasarkan hasil dari perhitungan $Q$-square dapat dilihat bahwa nilai $Q$-square sebesar 0,2025. Karena hasil nilai $Q$-square > 0 , dapat disimpulkan bahwa variabel kemanfaatan dan kemudahan memiliki tingkat prediksi yang baik terhadap penerimaan penggunaan e-learning di STMIK STIKOM Bali.

\section{Pengujian Hipotesis}

Pengujian hipotesis pada penelitian dilakukan dengan melihat nilai t-hitung pada masing-masing path. Untuk mendapat hasil output pengujian hipotesis maka dilakukan bootstrapping sehingga didapatkan nilai $t$ hitung seperti pada Tabel 6

Tabel 6. Nilai t-hitung

\begin{tabular}{|c|c|c|c|c|}
\hline $\begin{array}{c}\text { Variable } \\
\text { Bebas }\end{array}$ & $\begin{array}{c}\text { Variable } \\
\text { Terkait }\end{array}$ & $\begin{array}{c}\text { T- } \\
\text { Tabel }\end{array}$ & $\begin{array}{c}\text { T- } \\
\text { Statistik }\end{array}$ & Ket \\
\hline PE & BIUS & 1.96 & 1.187 & $\begin{array}{c}\text { Tidak } \\
\text { Signifikan }\end{array}$ \\
\hline EE & BIUS & 1.96 & 1.613 & $\begin{array}{c}\text { Tidak } \\
\text { Signifikan }\end{array}$ \\
\hline SI & BIUS & 1.96 & 2.242 & Signifikan \\
\hline FC & BIUS & 1.96 & 1.385 & $\begin{array}{c}\text { Tidak } \\
\text { Signifikan }\end{array}$ \\
\hline
\end{tabular}

Dari table 6 diperoleh hasil pengujian hipotesis sebagai berikut :

a. HI : Performacy Expectacy mempunyai pengaruh positif terhadap Behavior In Use System

Variable Performacy Expectacy dianggap tidak memiliki pengaruh positif pada Behavior In Use System. Dimana hal ini dapat dilihat dari nilai $\mathrm{t}$ untuk hubungan Performacy Expectacy dan Behavior In Use System memiliki nilai lebih kecil dari t-tabel yaitu 1,187

b. H2 : Effort Expectacy mempunyai pengaruh positif terhadap Behavior In Use System

Variable Effort Expectacy dianggap tidak memiliki pengaruh positif pada Behavior In Use System. Dimana hal ini dapat dilihat dari nilai t untuk hubungan Effort Expectacy dan Behavior In Use System memiliki nilai lebih kecil dari t-tabel yaitu 1,613

c. H3 : Social Influence mempuyai pengaruh positif terhadp Behavior In Use System 
Variable Social Influence dianggap memiliki pengaruh positif pada Behavior In Use System. Dimana hal ini dapat dilihat dari nilai t untuk hubungan Social Influence dan Behavior In Use System memiliki nilai lebih besar dari t-tabel yaitu 2,242

d. H4 : Facilitating Condition mempuyai pengaruh positif terhadap Behavior In Use System

Variable Social Influence dianggap memiliki pengaruh positif pada Behavior In Use System. Dimana hal ini dapat dilihat dari nilai t untuk hubungan Social Influence dan Behavior In Use System memiliki nilai lebih besar dari t-tabel yaitu 1,385

\section{SIMPULAN}

Kesimpulan yang dapat ditarik dari penelitian ini adalah sebagai berikut :

a. Model struktural yang diajukan dalam penelitian ini yang menyangkut hubungan antara Performacy Expectacy, Effort Expectacy, Social Influence dan Facilitating Condition dengan Behavior In Use System penggunaan e-learning STMK STIKOM Bali sudah dapat dianggap valid dan reliabel dengan melihat pada nilai pengujian outer model dan inner model yang sudah memiliki nilai diatas nilai batas yang seharusnya.

b. Dari hasil hipotesis dihasilkan bahwa hubungan antara Performacy Expectacy, Effort Expectacy, Social Influence dan Facilitating Condition dengan Behavior In Use System hanya Social Influence dengan Behavior In Use System bernilai 2,242 diatas 1,96 yang hasilnya signifikan.

\section{DAFTAR PUSTAKA}

[1] Handayani Trie, Sudiana. (2015). Analisis penerapan model UTAUT (Unified Theory Acceptance and use technology) terhadap perilaku pengguna system informasi (Studi Kasus : Sistem Informasi Akademik pada STTNAS Yogyakarta. Jurnal Angkasa, November $2015(165-180)$
[2] Siahaan, Micheal Sony dan widodo, prabowo pudjo (-). Kadian Unified

Theory Acceptance and use of technology dalam penggunaan open source software database management system: Studi Kasus Universitas Indraprasta Negeri PGRi. Jurnal Ilmiah Program Pascasarjana Magister Ilmu Komputer STMIK Nusa Mandiri

[3] V. Venkatesh( 2003), M.G. Morris, G.B. Davis, F.D. Davis, "User acceptance of information technology: toward a unified view, " MIS Quarterly, vol. 27, pp. 42547

[4] Bisri ,Khasan., Samsudi.,dan Supratono.(2009). Efektifitas Penggunaan Metode Pembelajaran Elearning berbasis Browser Based Training terhadap prestasi belajar siswa pada kompetensi pemeliharaan/servis transmisi manual dan komponen.Jurnal PTM Volume 9,No.1, Juni 2009(214260)

[5] Sedana I Gusti Nyoman dan Wijaya St. Wisnu (2010). UTAUT Model For Understanding Learning Management System.Internetworking Indonesia Jurnal Volume 2/No.2 $2010(27$ - 32) 